Supporting Information

\title{
Tough Adhesion of Freezing- and Drying-Tolerant Transparent Nanocomposite Organohydrogels
}

Beibei Liu, Feibo Li, Pengying Niu, Huanjun Li*

* School of Chemistry and Chemical Engineering, Beijing Institute of Technology, Beijing 100081, P. R. China, E-mail: lihj@bit.edu.cn 


\section{Table of Contents}

1. Supplementary Tables .................................................................................................

2. Supplementary Figures and Discussion ....................................................................4

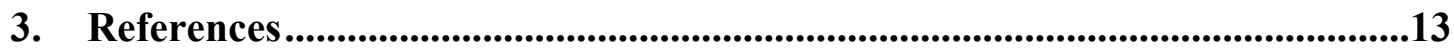




\section{Supplementary Tables}

Table S1 Compositions for Al-NC-G gels and Al-NC-W gels.

\begin{tabular}{|c|c|c|c|c|c|c|c|}
\hline Sample & $\begin{array}{c}\mathrm{AA} \\
(\mathrm{g})\end{array}$ & $\begin{array}{c}\mathrm{AM} \\
(\mathrm{g})\end{array}$ & $\begin{array}{c}\mathrm{Al}(\mathrm{OH})_{3} \mathrm{NPs} \\
(\mathrm{wt} \%)\end{array}$ & $\begin{array}{c}\text { IR2959 } \\
(\mathrm{g})\end{array}$ & $\begin{array}{c}\text { Water } \\
(\mathrm{g})\end{array}$ & $\begin{array}{c}\text { glycerol } \\
(\mathrm{g})\end{array}$ & $\begin{array}{c}\text { Glycerol } \\
\text { ratio }\end{array}$ \\
\hline $\mathrm{AM} 90 \mathrm{Al} 2 \mathrm{~W}$ & 0.22 & 1.93 & 2.00 & 0.04 & 10.00 & 0.00 & $0: 1$ \\
\hline AM90A12G0.5 & 0.22 & 1.93 & 2.00 & 0.04 & 6.67 & 3.33 & $1: 2$ \\
\hline AM90Al2G1 & 0.22 & 1.93 & 2.00 & 0.04 & 5.00 & 5.00 & $1: 1$ \\
\hline AM90Al2G2 & 0.22 & 1.93 & 2.00 & 0.04 & 3.33 & 6.67 & $2: 1$ \\
\hline
\end{tabular}

Table S2 Comparisons of mechanical properties including tensile strength, tensile strain and the work of fracture of AM90A12G1 gels and AM90A12W gels before and after being stored for 30 days at $25^{\circ} \mathrm{C}$ or $-20^{\circ} \mathrm{C}$.

\begin{tabular}{|c|c|c|c|}
\hline Sample & $\begin{array}{c}\text { Tensile strength } \\
(\mathrm{MPa})\end{array}$ & $\begin{array}{c}\text { Tensile strain } \\
(\%)\end{array}$ & $\begin{array}{l}\text { The work of fracture } \\
\qquad\left(\mathrm{KJ} \mathrm{m}^{-3}\right)\end{array}$ \\
\hline $\begin{array}{c}\text { Initial } \\
\text { (AM90Al2W) }\end{array}$ & $0.50 \pm 0.11$ & $418.46 \pm 10.56$ & $794.50 \pm 77.70$ \\
\hline $\begin{array}{c}25^{\circ} \mathrm{C} \text { for } 30 \text { days } \\
(\mathrm{AM} 90 \mathrm{Al} 2 \mathrm{~W})\end{array}$ & 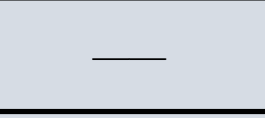 & 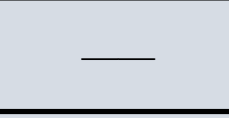 & - \\
\hline $\begin{array}{c}-20^{\circ} \mathrm{C} \text { for } 30 \text { days } \\
\text { (AM90Al2W) }\end{array}$ & - & 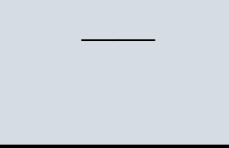 & - \\
\hline $\begin{array}{c}\text { Initial } \\
(\mathrm{AM} 90 \mathrm{Al} 2 \mathrm{G} 1)\end{array}$ & $0.86 \pm 0.09$ & $546.75 \pm 57.95$ & $1998.63 \pm 102.90$ \\
\hline $\begin{array}{l}25^{\circ} \mathrm{C} \text { for } 30 \text { days } \\
\text { ( AM90Al2G1) }\end{array}$ & $1.01 \pm 0.01$ & $423.66 \pm 71.05$ & $1549.35 \pm 107.72$ \\
\hline $\begin{array}{l}-20^{\circ} \mathrm{C} \text { for } 30 \text { days } \\
\text { ( AM90A12G1) }\end{array}$ & $0.93 \pm 0.06$ & $481.23 \pm 74.38$ & $1819.93 \pm 109.80$ \\
\hline
\end{tabular}

“__ represented no available data due to dehydration or freezing. 


\section{Supplementary Figures and Discussion}

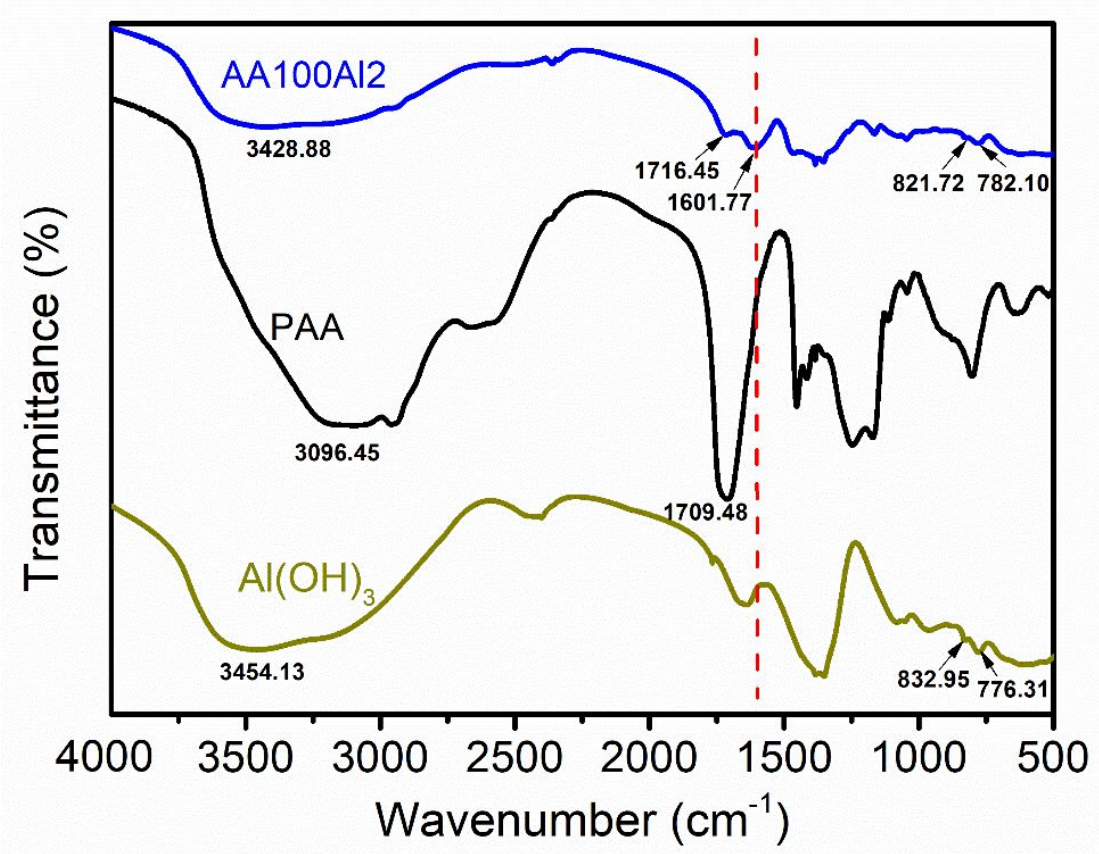

Figure S1 The FT-IR spectrums of AA100A12 hydrogel, PAA hydrogel, $\mathrm{Al}(\mathrm{OH})_{3}$ nanoparticles. For AA100A12 hydrogel, a new peak at $1601.77 \mathrm{~cm}^{-1}$ corresponded to the asymmetric stretching vibration of the carboxylate group, illustrating that polymer chains were attached to the nanoparticle surface by ionic coordination bonds. ${ }^{1}$ The peak of PAA hydrogel at $1709.48 \mathrm{~cm}^{-1}$ corresponded to the stretching vibration peak of $\mathrm{C}=\mathrm{O}$. The peak of AA100A12 hydrogel at $1716.45 \mathrm{~cm}^{-1}$ also corresponded to the $\mathrm{C}=\mathrm{O}$ stretching vibration peak. ${ }^{2}$ This result indicated that not all carboxyl groups in the polymer chains form coordination bonds with $\mathrm{Al}(\mathrm{OH})_{3}$, and there are still free carboxyl groups. In the AA100A12 gel, the amount of $\mathrm{Al}(\mathrm{OH})_{3}$ nanoparticles was fixed at $2 \mathrm{wt} \%$ (relative to weight of water) and acrylic acid (AA) was chosen as the only polymer monomer (concentration of $3 \mathrm{~mol}^{\mathrm{L}^{-1}}$ ). 


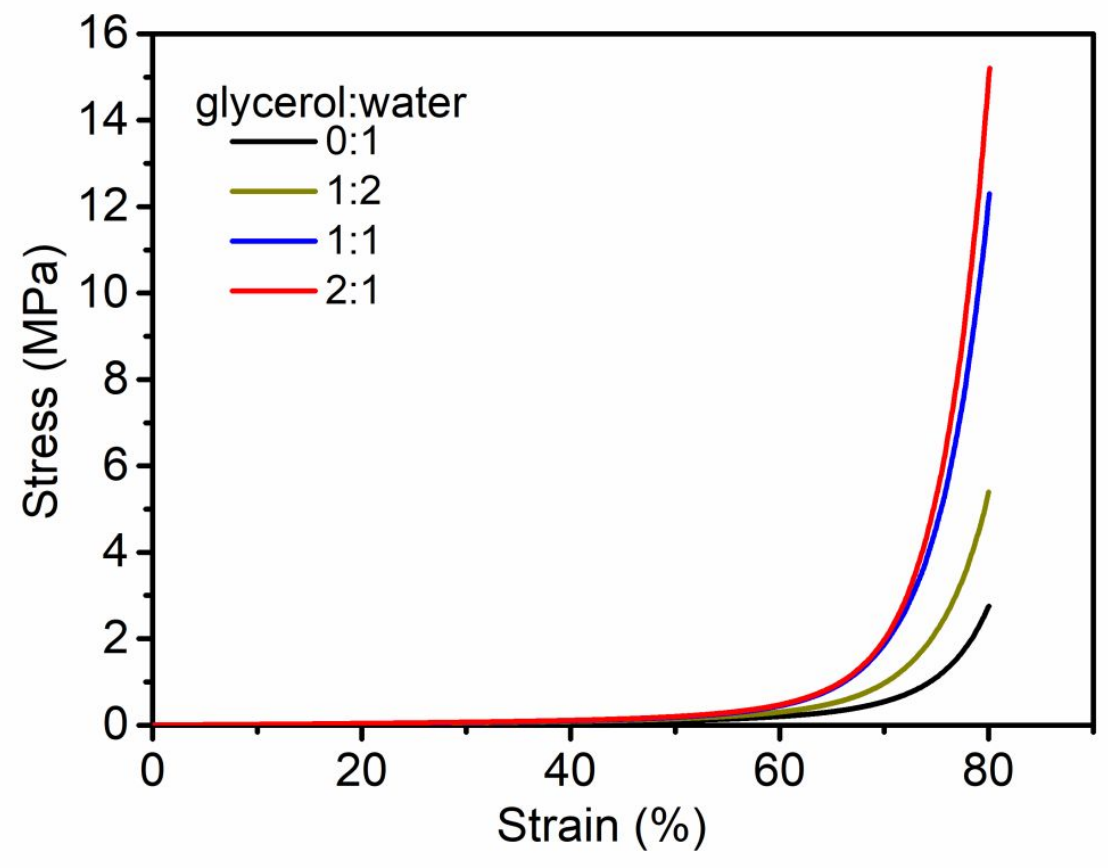

Figure S2 Compressive strain-stress curves of the AM90A12Gy gel, where y represented the solvent mass ratio ( $\mathrm{y}=$ glycerol: water).

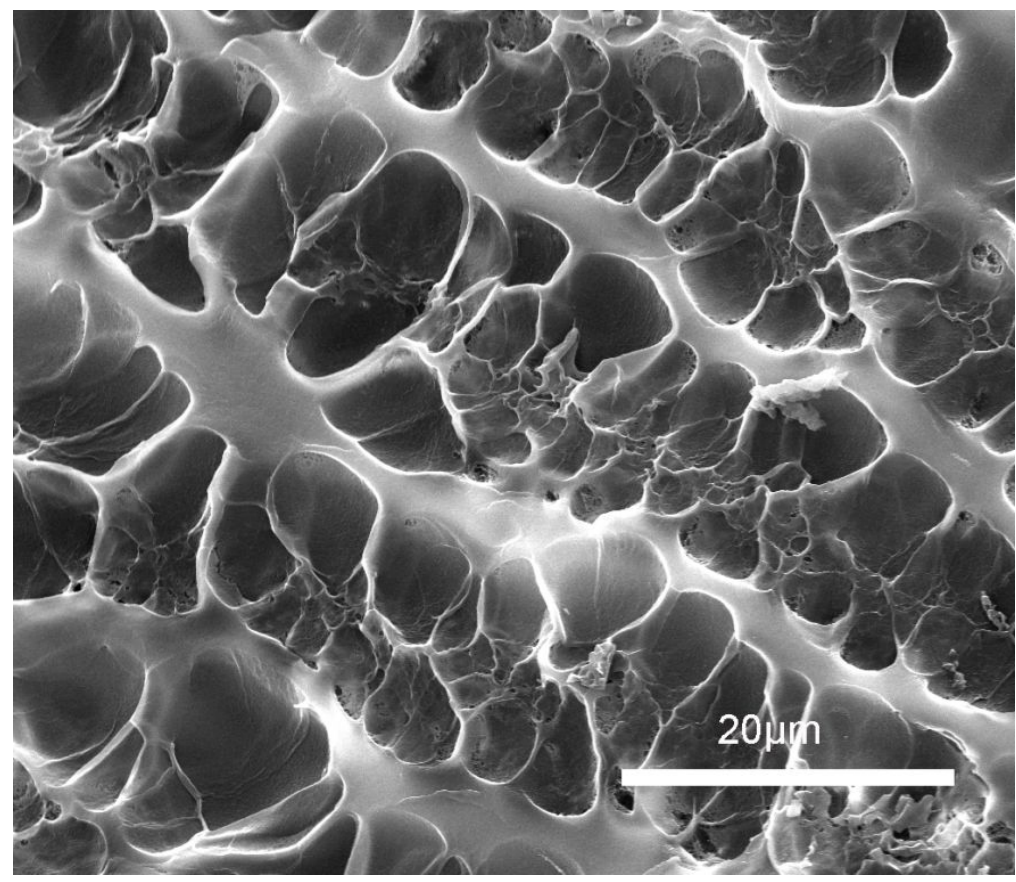

Figure S3 SEM image of the surface of the Al-NC-G gel. 


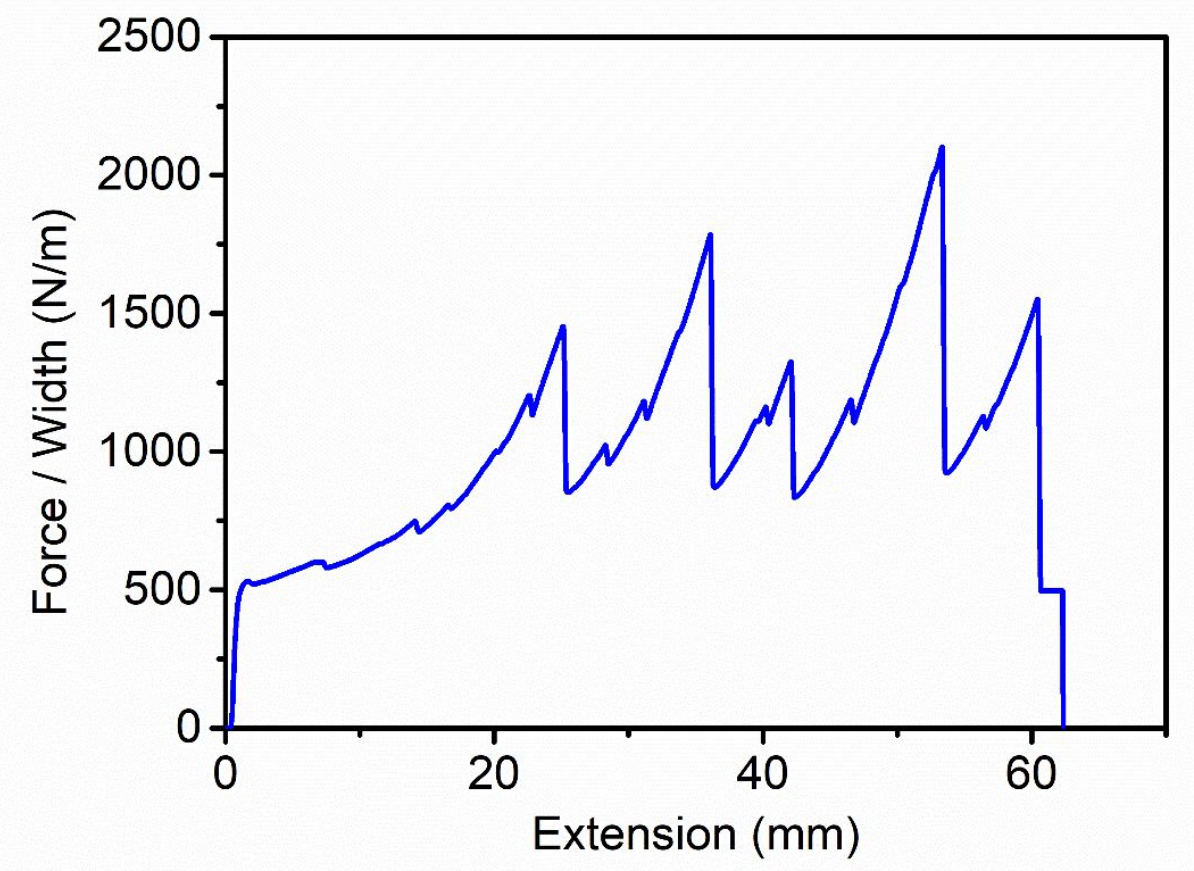

Figure S4 The force-extension curve of the T-peeling test of the adhered AM90A12G1 gel by using PAA as a bridging polymer.

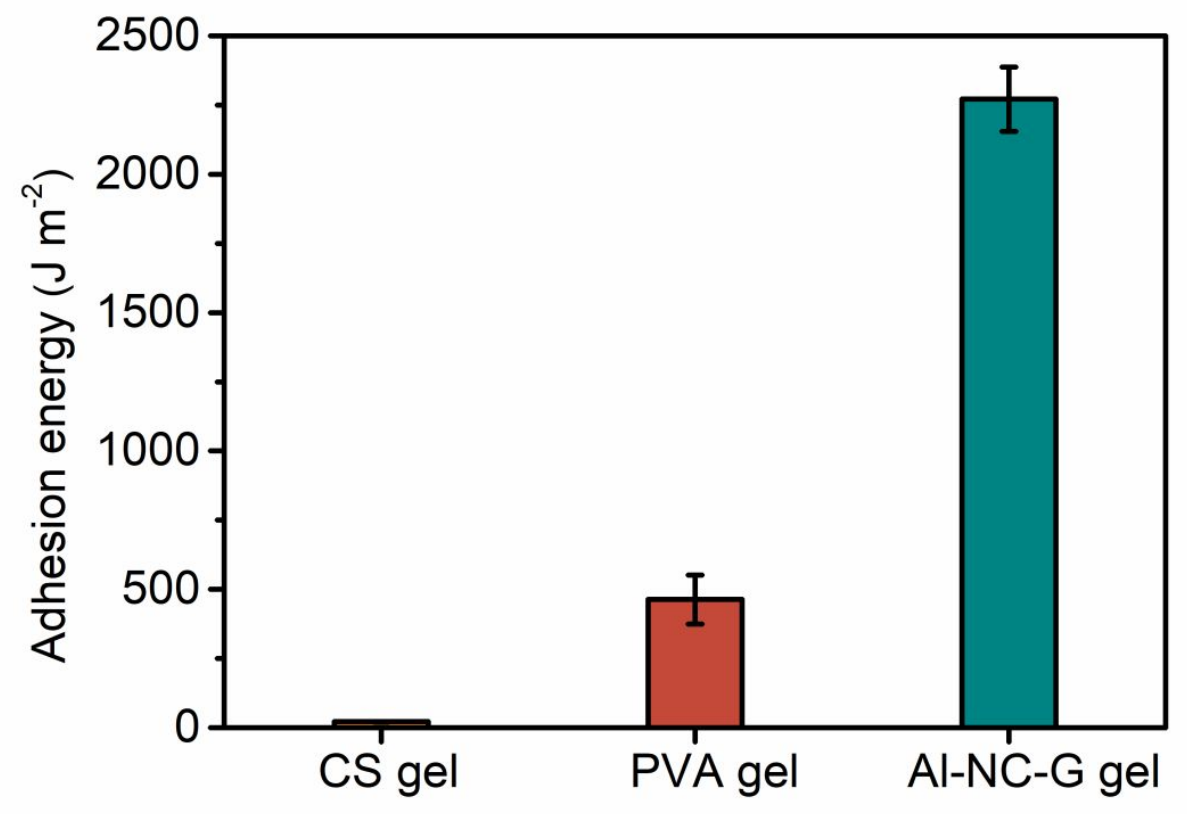

Figure S5 The effect of different gel substrates on the interfacial adhesion energy. 
The preparation of CS gel: Chitosan (CS) was dissolved in an aqueous solution of 1 $\mathrm{wt} \%$ acetic acid to form a $2 \mathrm{wt} \%$ solution and it was kept for at least $24 \mathrm{~h}$ before use. Then the desired amount of CS solution was poured into Petri dish to let the water evaporate for the formation of film. The free-standing film was obtained by directly peeled off from the Petri dish. The dried film was immersed in $1.0 \mathrm{wt} \% \mathrm{NaOH}$ solution for $1 \mathrm{~h}$ to neutralize the extra acetic acid, and then washed in ultrapure water to remove the residual $\mathrm{NaOH}$ in the films. Finally, the CS films were further immersed in a large amount of distilled water for $4 \mathrm{~h}$ to reach the swollen equilibrium and then the CS hydrogel film was obtained.

The preparation of PVA gel: PVA solution of $10 \mathrm{wt} \%$ was prepared by dissolving a desired amount of PVA powder at $90{ }^{\circ} \mathrm{C}$ for $6 \mathrm{~h}$ in deionized water under vigorous stirring. Then, the PVA solution was transferred into an open transparent mold to form PVA hydrogel via a classic freezing/thawing method (i.e., cooling to $-20{ }^{\circ} \mathrm{C}$ for $12 \mathrm{~h}$ and then thawed at room temperature for $3 \mathrm{~h}$, three cycles). 


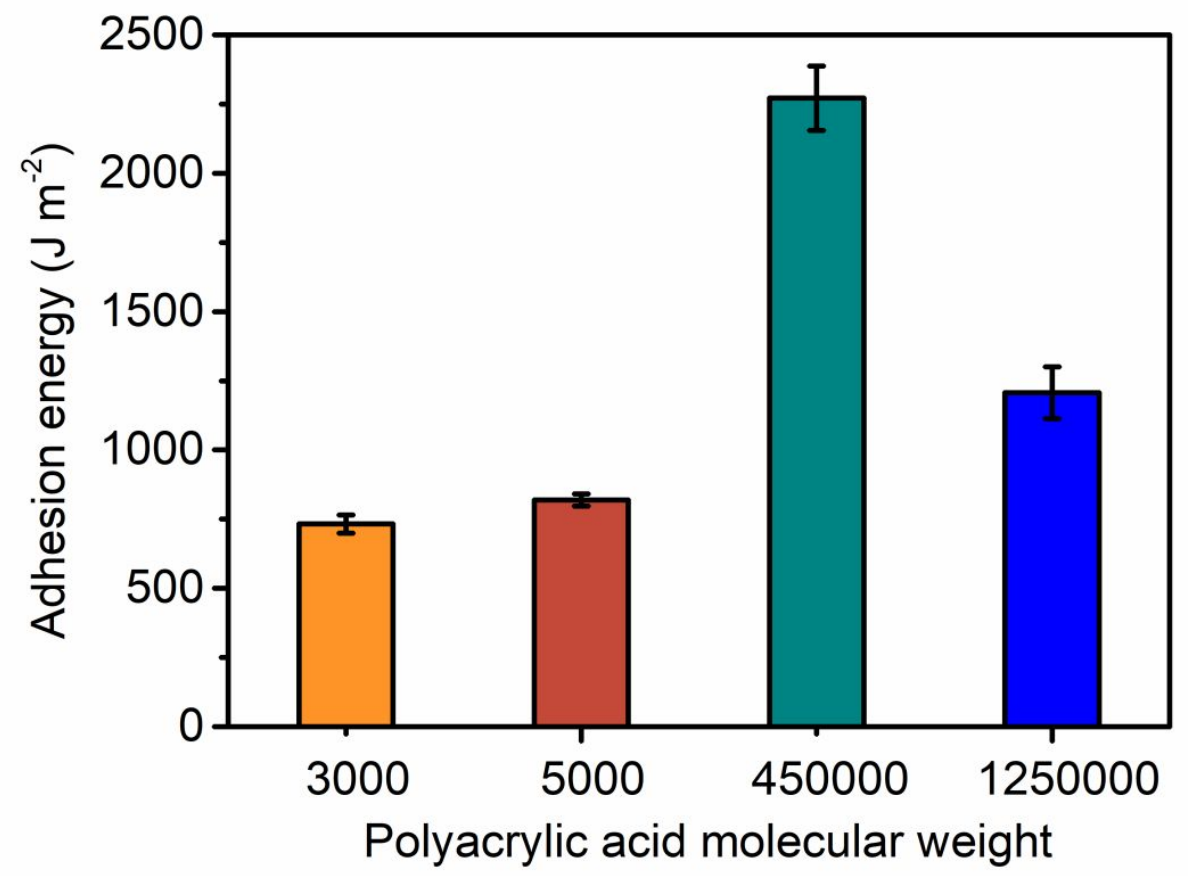

Figure S6 The effect of polyacrylic acid molecular weights (concentration fixed to 6 wt \%) on the adhesion energy of adhered AM90A12G1 gel.

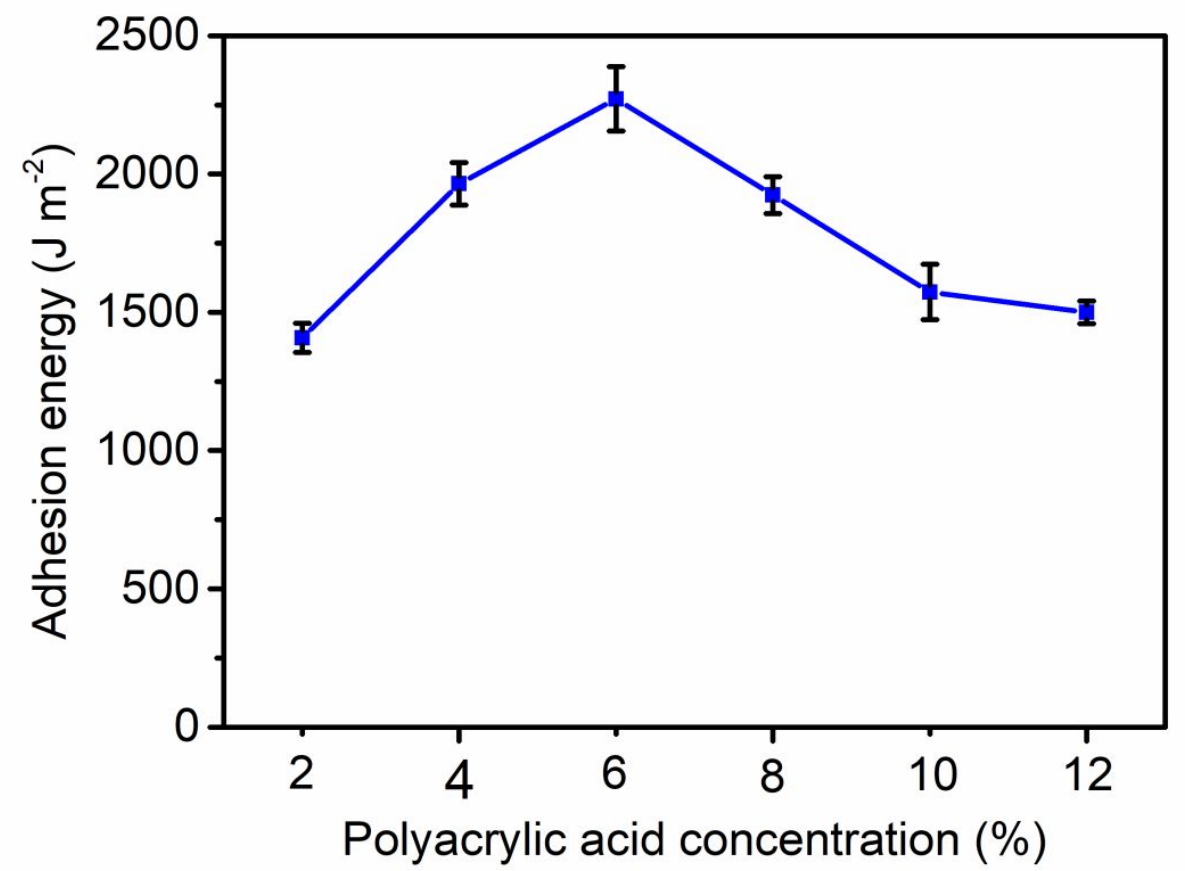

Figure S7 The relationship between the adhesion energy and the polyacrylic acid concentration (polyacrylic acid with a molecular weight of 450000). 


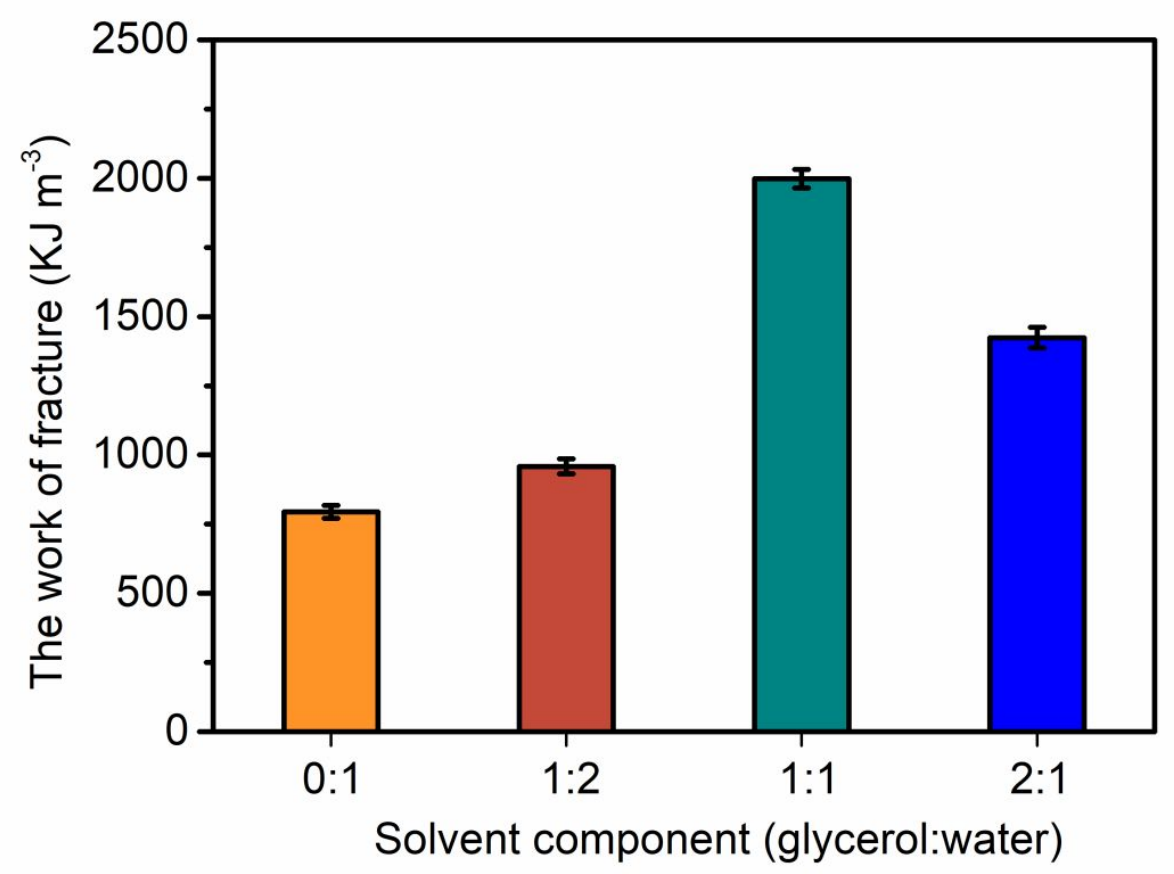

Figure S8 The work of fracture of adhered AM90A12Gx gels prepared by different solvent components $(\mathrm{x}=$ glycerol: water $)$.

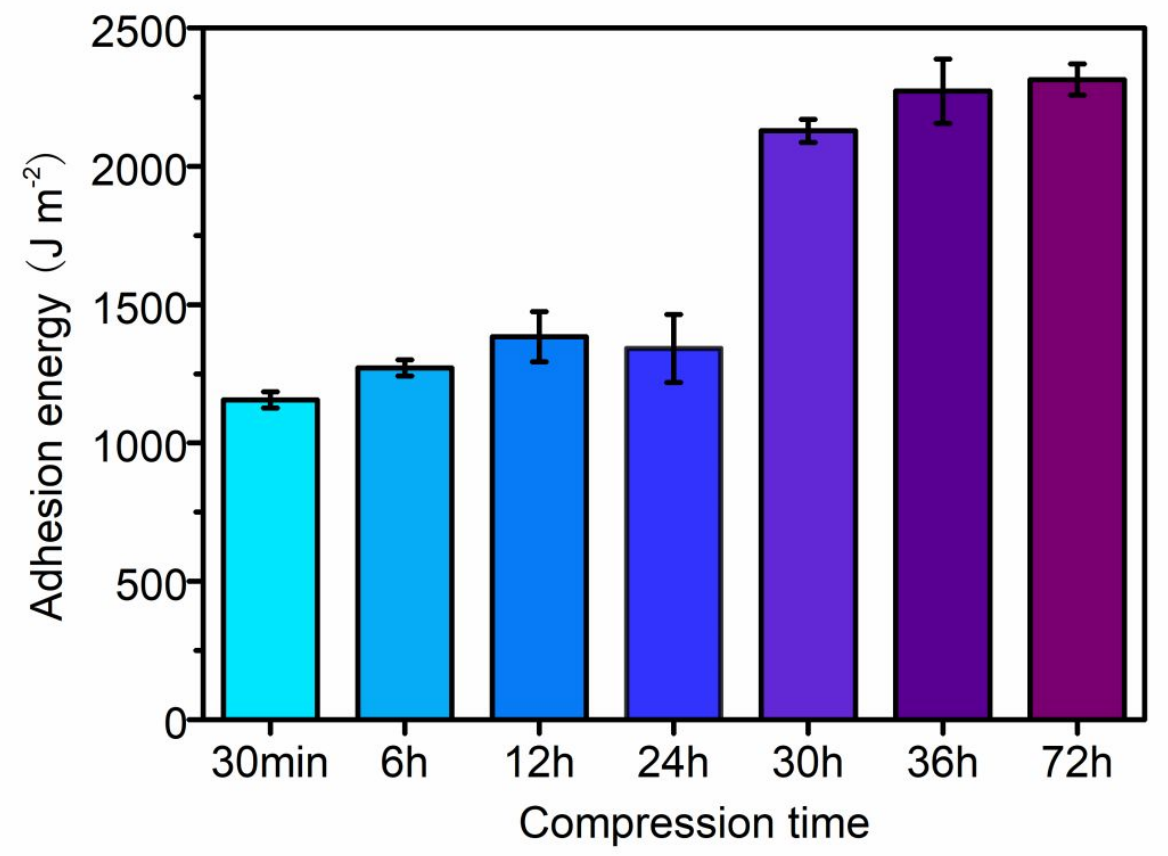

Figure S9 The adhesion energy of the adhered AM90A12G1 gels with different compressive times during the preparation process. 


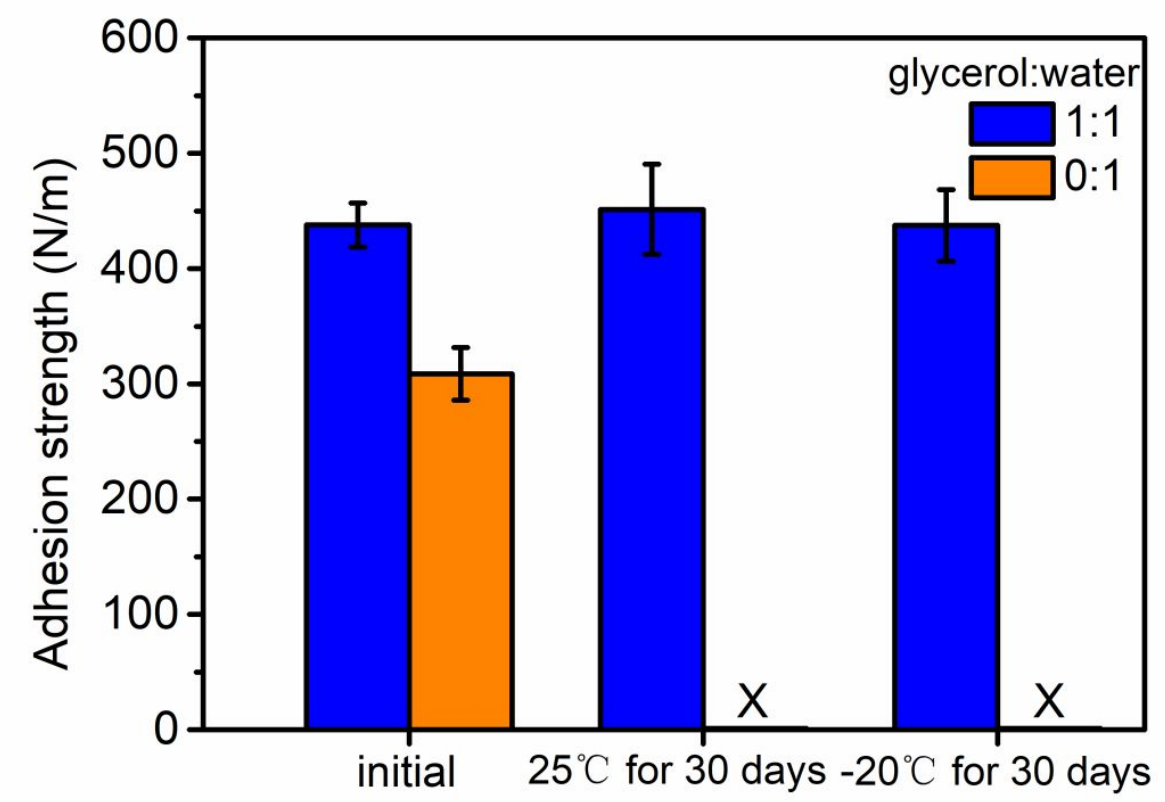

Figure S10 Comparisons of the adhesion strength of Al-NC-G gels and Al-NC-W gels, where X represented no data due to dehydration or freezing of Al-NC-W gels.

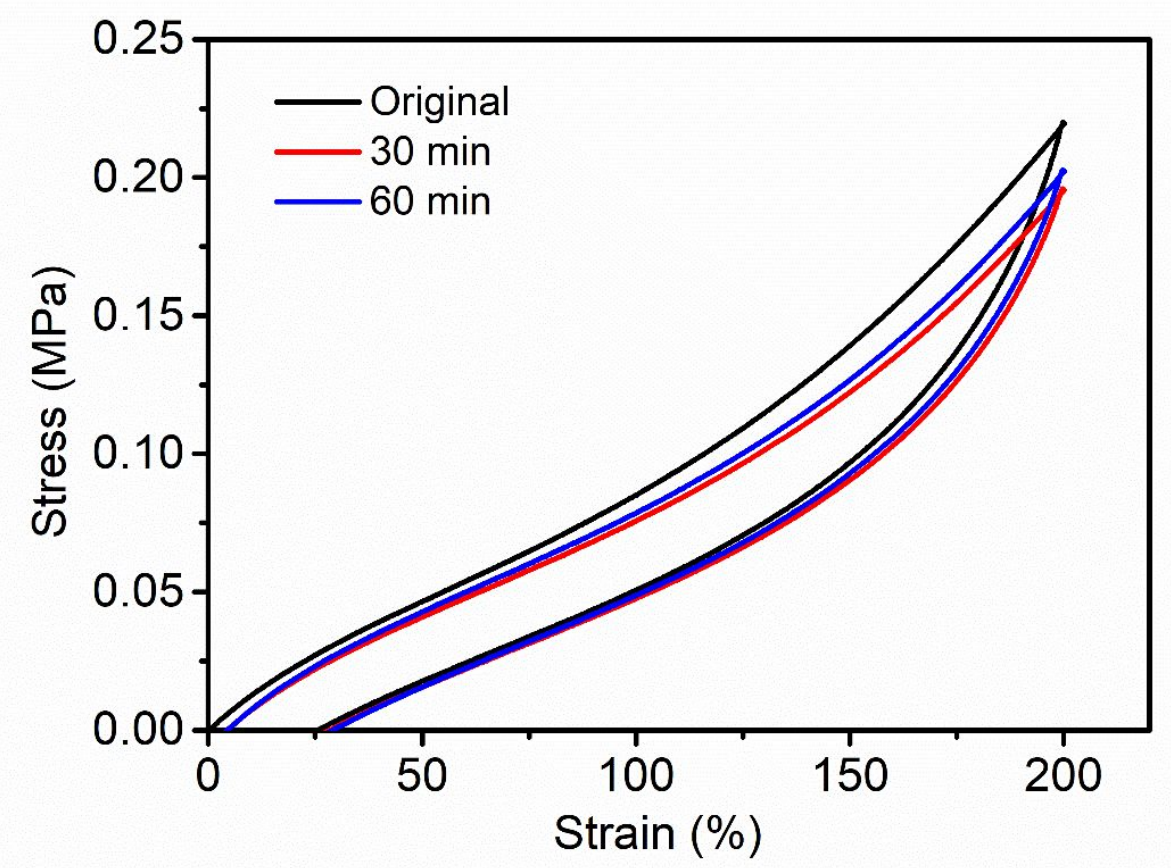

Figure S11 The self-recovery property of the AM90A12G1 gel. 


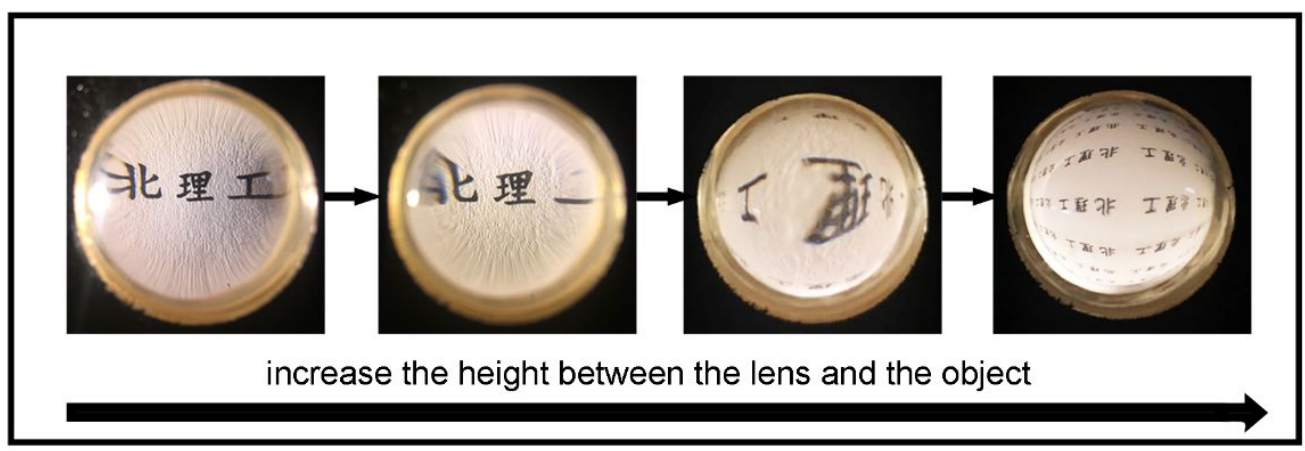

Figure S12 The impact of height between the AM9A12G1 gel lens and the object on the image status. (the content of liquid within the AM9A12G1 gel lens was fixed at 10 $\mathrm{ml}$, and the inner diameter of the lens was $30 \mathrm{~mm}$ ).

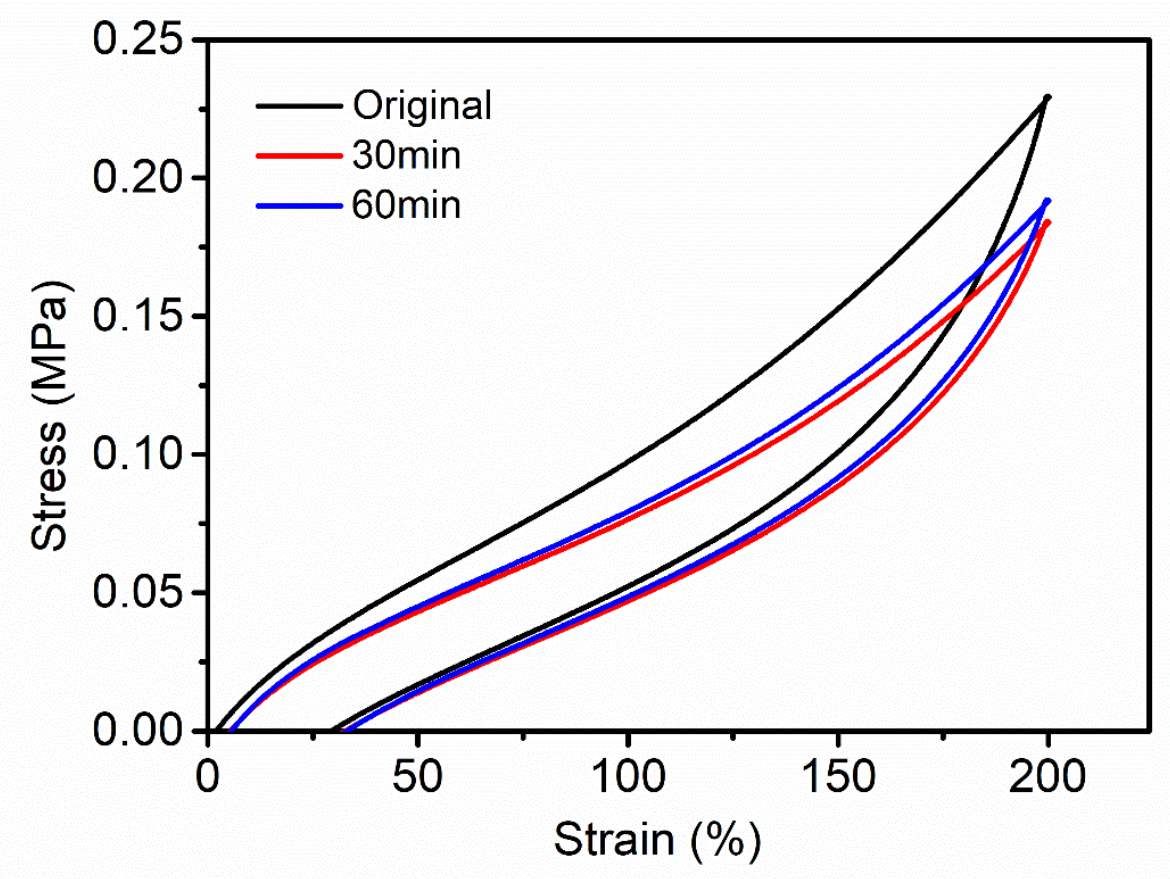

Figure S13 The self-recovery property of the AM90A12G1 gel that was placed in the refrigerator for 30 days $\left(\mathrm{T}=-20^{\circ} \mathrm{C}, \mathrm{RH}=70 \%\right)$. 


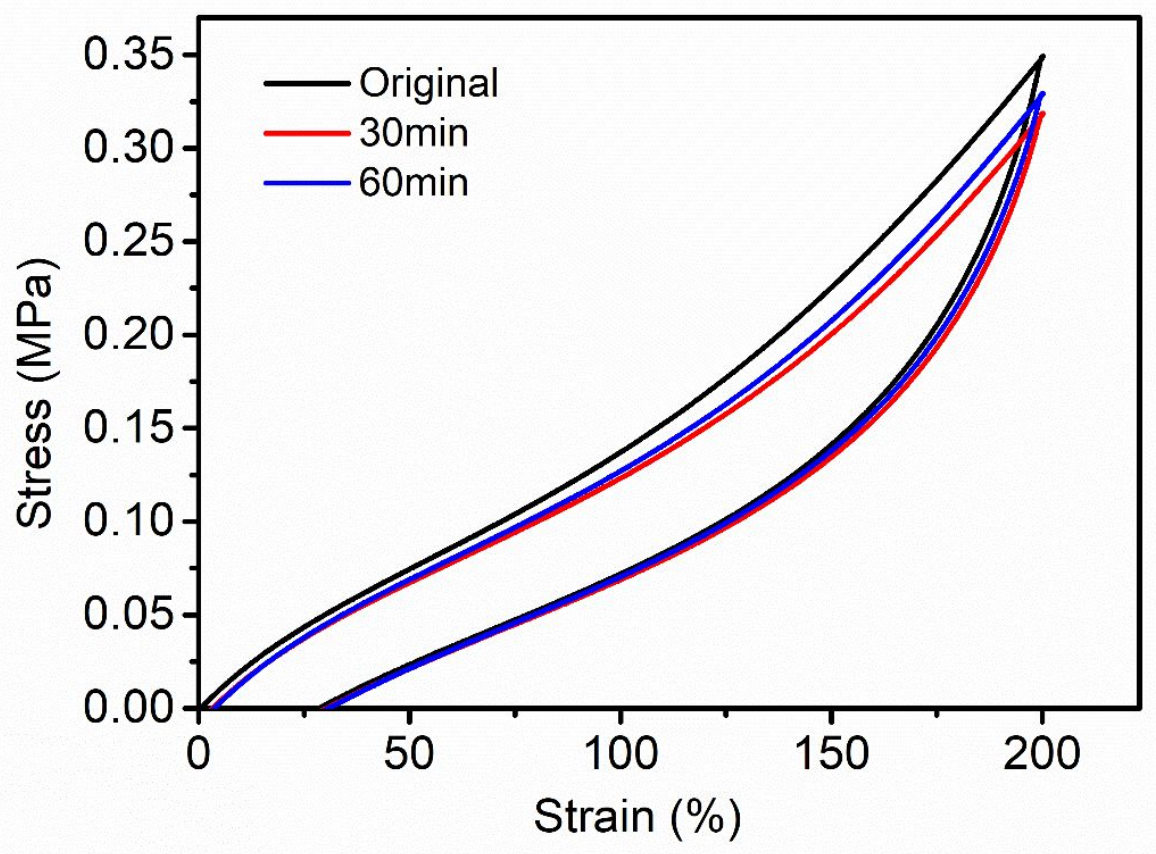

Figure S14 The self-recovery property of the AM90A12G1 gel that was placed at room temperature for 30 days $\left(\mathrm{T}=25^{\circ} \mathrm{C}, \mathrm{RH}=50 \%\right)$. 


\section{References}

(1) Li, F.; Zhang, G.; Wang, Z.; Jiang, H.; Yan, S.; Zhang, L.; Li, H. Strong Wet Adhesion of Tough Transparent Nanocomposite Hydrogels for Fast Tunable Focus Lenses. ACS Appl. Mater. Interfaces 2019, 11, 15071-15078.

(2) Jian Dong, Y. O., Kenichi Nakashima. Infrared, Raman, and Near-Infrared Spectroscopic Evidence for the Coexistence of Various Hydrogen-Bond Forms in Poly(acrylic acid). Macromolecules 1997, 30, 1111-1117. 